\title{
Divisão territorial do trabalho e produtividade regional fluminense nos anos 2000
}

\author{
Helcio de Medeiros Junior ${ }^{1}$
}

\begin{abstract}
RESUMO
O Estado do Rio de Janeiro tem passado por mudanças que privilegiaram regiões receptoras dos investimentos e limítrofes a elas, com características industriais e principalmente naquela em que a acumulação de capital obtida na atividade de extração de petróleo tem levado a que o desenvolvimento seja desigual (Smith, 1988), com menor participação das regiões esquecidas por inversões. Em razão do desenvolvimento em curso, a divisão territorial do trabalho fluminense, neste trabalho identificada por critérios alternativos de participação na geração da renda e indicadores de análise regional (Quociente de localização-QL e Coeficiente de especialização-CE), se alterou. Tendo em vista que nas regiões em que a densidade industrial é mais elevada há aumento da capacidade de inovação, de disseminação tecnológica e produção (Rosendo e Britto, 2011), a tendência de elevação dos níveis de produtividade regional (Trotsky, 1977) irão alargar a distância que a região Norte Fluminense já atingiu ante as demais.
\end{abstract}

Palavras-chave: Divisão territorial do trabalho; Desenvolvimento regional; Renda interna; Estado do Rio de Janeiro; Produtividade regional

\begin{abstract}
The State of Rio de Janeiro has been going by changes that privileged receiving areas of the investments and bordering to them, with industrial characteristics and mainly in that in that the capital accumulation obtained in the activity of extraction of petroleum has been taking the one to be unequal (Smith, 1988), with smaller participation of the regions forgotten by inversions. In reason of the development in course, the territorial division of the fluminense labor, in this work identified by alternative criteria of participation in the generation of the income and indicators of regional analysis (Quotient of location-QL and Coefficient of specialization-CE), she lost temper. Tends in view that in the regions in that the industrial density is higher there is increase of the innovation capacity, of technological dissemination and production (Rosendo and Britto, 2011), the tendency of elevation of the levels of regional productivity (Trotsky, 1977) they will enlarge the distance that the Norte Fluminense region already reached before the others.
\end{abstract}

Keywords: Territorial division of the labor; Regional development; Income interns; State of Rio de Janeiro; Regional productivity

\footnotetext{
${ }^{1}$ Economista pela FEF, mestre em Economia Empresarial pela UCAM, doutor em Planejamento Urbano e Regional pela UFRJ e pesquisador do Laboratório Estado, Economia e Território (LESTE) do IPPUR/UFRJ. E-mail: hmedeirosjunior@gmail.com
} 


\section{Introdução}

As mudanças pelas quais o Estado do Rio de Janeiro tem passado desde o século XX resultaram em nova configuração regional da atividade econômica e também na ascensão e prevalência de atividades ligadas à extração mineral como segmentos mais dinâmicos e produtivos da indústria. Tais efeitos levaram a que o desenvolvimento fluminense se desse de maneira desigual, com a prevalência das regiões privilegiadas por investimentos, acumulação de capital e geração de lucros, em detrimento das demais, que por eles não foram alcançadas.

As mudanças regionais decorrentes dos investimentos em termos de mobilidade populacional, empregos, geração de negócios e riquezas evidenciaram que alterações na divisão territorial do trabalho fluminense estariam em curso, e que poderiam ser observadas a partir de indicadores usualmente utilizados, tais como a renda gerada por setor econômico, com evidências de elevação da produtividade média regional naquelas com maior participação industrial, como sugerido por Trotsky (1977).

Assim, este trabalho se propõe a identificar como se caracteriza a divisão territorial do trabalho no território fluminense, e se as regiões que têm sido eleitas pelo capital para acumulação e obtenção de taxas elevadas de lucro seriam aquelas que apresentariam resultados mais significativos em termos de produtividade do trabalho. Para alcançar os objetivos a que se propõe, o presente texto se estrutura em quatro sessões, além desta Introdução, tendo a primeira considerações sobre a divisão social e territorial do trabalho; a segunda a caracterização da divisão territorial do trabalho fluminense; a terceira exporá os níveis de produtividade regionais e a quarta e última sessão trará elementos à guisa de conclusão.

\section{Divisão social e territorial do trabalho}

Desde Adam Smith (1996), a partir da observação do processo produtivo em uma fábrica de alfinetes, a divisão social do trabalho tornou-se a categoria analítica para designar a especialização de atividades na sociedade, cujo resultado, enquanto produto do trabalho, circule na condição de mercadoria, ou não. A fragmentação do processo de produção a partir da repartição do trabalho em numerosas operações especializadas leva ao aumento da produtividade e atribui valores diferenciados a cada tarefa executada por trabalhadores 
diversos, ou um grupo deles. Para o capitalista contratante, a divisão social do trabalho leva à elevação da produtividade em decorrência da redução do custo da força de trabalho, dado o aumento da produção por unidade de tempo. Em vista desta particularidade, Borchardt (1982) pondera que a divisão do trabalho na sociedade tem por intermediários a venda e compra de produtos nos diversos ramos de trabalho, e a conexão dos trabalhos parciais na manufatura é intermediada pelo mesmo capitalista que compra diferentes forças de trabalho, que, ao empregá-las, as combina. Assim, a divisão manufatureira do trabalho supõe a concentração dos meios de produção nas mãos de um capitalista, e é uma criação específica do modo de produção capitalista.

Para Marx (1989), a divisão social do trabalho diz respeito ao trabalho humano, e se estabelece em atividades necessárias à reprodução da vida, mas não se limita à visão de Smith. Segundo ele, há dois tipos de divisão do trabalho: entre os trabalhadores, e na troca. De acordo com Mohun (1988), a primeira se dá na produção, "entre o capital e o trabalho em seu confronto dentro do processo de produção" (Mohun, 1988:112), e tem como resultado o produto social do trabalho coletivo; já a segunda é um sistema complexo das formas diferentes de trabalho realizadas em particular por produtores privados, ou uma divisão do trabalho que se realiza na troca entre capitalistas individuais e independentes que competem uns com os outros. Ainda que pouco explorado, este segundo tipo de divisão do trabalho é central para o capitalismo, haja vista estar nele a possibilidade de extração da mais-valia. Como menciona Daniel Rodrigues (2008):

\begin{abstract}
A produção de valor é algo inseparável da sua possibilidade de ser útil e de ser trocada e no capitalismo atinge o máximo da polarização da produção. No caso, se nos primeiros processos da humanidade o centro da produção era sua utilidade e a troca era incipiente, no seu desenvolvimento, a troca é o mecanismo para se atingir o sentido último dos produtos, especialmente, no capitalismo. A troca tem a centralidade para realização da mais-valia produzida. (Rodrigues, 2008:5)
\end{abstract}

O confronto entre capitalistas individuais e independentes leva à especialização e à luta pela realização da produção na troca de maneira a maximizar a acumulação, e no território se dá a busca de espaços que permitam a melhor forma de obtê-la. Marx observou que o resultado da disputa no território levava a que tipos de atividade se localizassem em áreas nas quais obtivessem os requisitos para o estabelecimento de seu modo de produção, gerando assim a divisão dos espaços: "A divisão territorial do trabalho, que confina ramos 
particulares de produção em distritos particulares de um país, recebe novo impulso da empresa manufatureira, a qual explora todas as particularidades" (Marx, 1996:468).

A visão de Marx da divisão do trabalho na troca, portanto, permite compreender por que o espaço geográfico das aglomerações urbanas oferece condições propícias para a acumulação de capital, com infraestruturas instaladas financiadas, o mais das vezes, pelo setor público. A cidade passa a ser o meio através do qual o capitalismo se utiliza do território para aumentar a taxa de lucro na disputa entre os capitalistas individuais e independentes, levando a que localidades também tenham valor de troca. Segundo Fredrich e Davidovich (1982):

\begin{abstract}
A cidade, a um tempo, desempenha um papel econômico fundamental no desenvolvimento do capitalismo e é modelada pelas necessidades da acumulação do capital. [...] A cidade concentra as condições gerais da produção capitalista e, ao fazê-lo, transforma-se em uma nova força produtiva com um valor de uso complexo para o capital. Neste sentido ela passa também a adquirir um valor de troca, na medida em que o espaço urbano vem se transformar em mercadoria. (Fredrich e Davidovich, 1982:541-542)
\end{abstract}

Por terem valor de troca, tal como mercadorias, as escolhas locacionais dos capitalistas em relação à cidade privilegiam aquelas que permitam, na troca, maior rentabilidade, haja vista que os custos de produção serão menores graças à redução dos custos de operação. A seletividade decorrente leva a que setores de atividade se aglomerem em espaços comuns (economias de aglomeração), e o processo de diferenciação espacial se estabeleça em áreas que disponham de boa infraestrutura, normalmente mais bem equipadas, em detrimento das menos equipadas.

A busca de vantagens de localização no território pelo capital, além disso, se dá de acordo com as condições históricas, políticas, econômicas e sociais, levando à concentração geográfica, à diferenciação entre os espaços e à especialização produtiva dos lugares, e torna desigual a distribuição da produtividade.

Portanto, a segmentação e valoração do espaço, comum à observada entre trabalhadores, confere à divisão social do trabalho uma expressão territorial, denominada divisão territorial, espacial, interurbana ou inter-regional do trabalho.

\title{
1.1 Desenvolvimento desigual e combinado e divisão territorial do trabalho
}

A diferenciação espacial promovida pelo capital leva a que cidades e regiões tenham níveis e dinâmicas de crescimento e desenvolvimento desiguais, haja vista que nos territórios 
eleitos para sua expansão ocorre a homogeneização mediante a padronização de processos, enquanto naqueles que não são alcançados por atividades econômicas que habitem a fronteira de expansão do capitalismo se estabelece um relativo "atraso", tornando o todo heterogêneo. Assim, nos territórios "adiantados" há convergência de processos (e concentração do capital), e nos demais, divergência (dispersão do capital).

A diferenciação mencionada não relega necessariamente as áreas atrasadas ao eterno subdesenvolvimento, nem impõe às mesmas passarem pelas etapas históricas das desenvolvidas para tornarem-se adiantadas. Trotsky (1977), longe de acreditar na possibilidade de desenvolvimentos autônomos das regiões atrasadas que replicariam etapas vividas pelos países centrais, defendeu que as mesmas combinariam inovações tecnológicas, políticas e culturais produzidas nos países avançados com relações sociais por vezes précapitalistas existentes em seu ambiente. A esta proposição denominou "Lei do desenvolvimento desigual e combinado", que explica a trama existente entre territórios desnivelados no plano internacional, nacional e regional, com variados níveis de desenvolvimento, em contextos multiescalares.

O desnível regional, por sua vez, não tornaria inviável o desenvolvimento do capitalismo, mas o favoreceria. Numa relação de dominação e dependência, as regiões adiantadas consumiriam elementos disponíveis em espaços menos desenvolvidos, em busca do aumento da taxa de lucro. A este respeito, Neil Smith (1988) identifica uma interseção entre as tradições geográfica e política ao sugerir que "uma teoria do desenvolvimento desigual oferece a chave-mestra para determinar o que caracteriza a geografia específica do capitalismo" (Smith, 1988:16-17). Sua lógica deriva de tendências opostas (diferenciação e igualização) e resulta da necessidade de imobilização contínua e desigual do capital fixo.

Cotidianamente, e para que alcance seus propósitos, o capital expressa seus anseios mediante o uso do codinome "mercado", ou através da ação conjunta ou coordenada de frações específicas que particularizam alguns de seus múltiplos interesses e, como um ente, reage às barreiras que lhe são impostas com retórica que dissimula e amedronta. Sua atuação, no entanto, se permitida como reclamada, não resulta em equilíbrio regional, mas em seu oposto, como já observou Myrdal (1972):

[...] há uma tendência inerente no livre jogo das forças do mercado a criar desigualdades regionais e que essa tendência tanto mais se agrava quanto mais pobre for um país, são as duas leis mais importantes do 
subdesenvolvimento e do desenvolvimento econômico no regime de laissezfaire. (Myrdal, 1972:63)

Tendo no espaço um meio de absorção de maiores taxas de lucro e acumulação, e no qual há, no mais das vezes, carência de recursos para gerar crescimento e já existem investimentos públicos em infraestrutura realizados, o capital encontra nas aglomerações urbanas receptividade para maximizar lucros e impor sua lógica. Para tanto, e mediante combinação de camadas de investimento em atividades específicas, estabelece bases econômicas e organização social que permitam seu desenvolvimento. Segundo Massey (1995), estas intervenções se subordinam às realizadas em outras regiões e se articulam a áreas geográficas distintas em relações de subordinação, conformando um sistema de interdependências. Neste ponto, emerge a questão das escalas, que, segundo Smith (1988), supõem a relação entre espaço absoluto e relativo, ou seja, que o capital ao localizar-se produz "ilhas de espaço absoluto num mar de espaço relativo" (Smith, 1988:135). Importa, pois, entre outros fatores, observar qual lógica levou o capital a localizar-se, historicamente em que momento do ciclo capitalista (expansão ou crise), a que espaço relativo se subordina, e em qual escala de ação se manifesta.

Portanto, a desigualdade produzida estabelece a diferenciação interna de territórios, que em termos concretos representa a divisão territorial do trabalho, e que evolui de acordo com o ritmo de expansão e crise do sistema capitalista.

\subsection{Indicadores de diferenciação do padrão da divisão territorial do trabalho}

Haja vista que o sistema urbano expressa um padrão de distribuição com base em características pretéritas, tais como as geradas pelas condições históricas, econômicas, políticas e sociais, bem como das inversões privadas e públicas e escolhas locacionais do capital, há indicadores que, segundo alguns autores, caracterizam a divisão territorial do trabalho, tais como: renda interna por ramos de atividade (Oliveira e Reichstul, 1973), estruturas produtivas, padrões ocupacionais, produtividade, capacidade de prover a população de bens de infraestrutura econômica e social (Faria, 1976), hierarquia funcional dos municípios, dinâmica demográfica e estrutura do emprego por ramos de atividade (Faria, 1980), estrutura socioeconômica (padrões de renda, consumo e de estrutura produtiva) e migração (Fredrich e Davidovich, 1982). Há ainda estudos que relacionam a divisão territorial do trabalho à rede urbana e, em decorrência, ao tamanho e especialização funcional das 
cidades, à estrutura socioeconômica, aos ritmos de crescimento e formas de concentração urbana (Corrêa, 2006).

Para os objetivos deste trabalho, em virtude da disponibilidade de informações sobre a geração de riquezas por setor econômico por região do Estado do Rio de Janeiro, far-se-á uso dos indicadores da renda interna por ramos de atividade e produtividade regional, conforme proposto por Oliveira e Reichstul (1973), para caracterizar as condições atuais da divisão territorial ou inter-regional do trabalho no território fluminense, bem como, apesar da exígua disponibilidade temporal de informações regionais, buscar perceber as mudanças pelas quais tem passado.

\section{Distribuição regional da atividade econômica setorial: localização, especialização e divisão territorial do trabalho}

Com o intuito de observar como se caracteriza a divisão territorial do trabalho fluminense, a partir das informações do Valor Adicionado Bruto (VAB) por setor econômico, buscar-se-á analisar num primeiro momento as participações de cada setor em cada região nos anos de 2000 e 2010 e, em seguida, utilizar indicadores de análise regional que permitam interpretações alternativas, quais sejam, o Quociente de Localização (QL) e o Coeficiente de Especialização (CE), conforme proposto por Simões (2005), Boisier (1980) e Instituto Nacional de Estatística (2003).

\subsection{Participações setoriais}

A geração de riqueza nas regiões fluminenses em 2010 demonstrou que, comparativamente à distribuição em 2000, se manteve o quadro de desconcentração, com perda de participação da Região Metropolitana e ganhos nas demais (Medeiros Junior, 2013a). Em 2000, 74,4\% do Valor Adicionado Bruto (VAB) do estado foi gerado na área metropolitana, contra 26,6\% no "interior"; dez anos depois, quase dez pontos percentuais a mais na participação do VAB (35,2\%) foram computados no "interior". Dentre as regiões interioranas, as responsáveis pelo ganho foram a Norte Fluminense com 5,1 pontos percentuais (pp) a mais, a das Baixadas Litorâneas $(+2,0$ pp), Costa Verde $(+1,9$ pp), Médio Paraíba $(+0,6$ pp) e Serrana (+0,1 pp). As duas regiões restantes, Noroeste Fluminense e 
Centro-Sul Fluminense, registraram perdas que, a exemplo do ganho da região Serrana, se caracterizou mais por manutenção da participação (Tabela 1).

Se considerados os setores econômicos divulgados pelo IBGE, nas regiões que agregaram mais pontos percentuais na participação em relação ao VAB do Estado do Rio de Janeiro a indústria foi determinante, com $+9,3$ pp na Norte Fluminense e $+3,2$ pp na das Baixadas Litorâneas, enquanto os serviços influenciaram o acréscimo na Costa Verde, com $+2,4$ pp. O resultado dos acréscimos na participação do VAB e dos setores econômicos foi que a região Norte Fluminense consolidou-se como a segunda maior do estado, com 12,5\%, cinco pontos percentuais a mais do que a terceira colocada, a do Médio Paraíba $(7,4 \%)$.

Tabela 1: Participação do valor adicionado bruto total e dos setores econômicos das Regiões de Governo no valor adicionado bruto do Estado do Rio de Janeiro - 2000-2010

\begin{tabular}{|c|c|c|c|c|}
\hline Estado e Regiões de Governo & Total & Agropecuária & Indústria & Serviços \\
\hline \multicolumn{5}{|l|}{2000} \\
\hline Estado do Rio de Janeiro & 100.0 & 100.0 & 100.0 & 100.0 \\
\hline Região Metropolitana & 74.4 & 12.6 & 55.2 & 81.0 \\
\hline Região Noroeste Fluminense & 1.2 & 11.1 & 0.8 & 1.3 \\
\hline Região Norte Fluminense & 7.4 & 24.7 & 19.4 & 3.4 \\
\hline Região Serrana & 4.1 & 22.2 & 3.0 & 4.2 \\
\hline Região das Baixadas Litorâneas & 3.9 & 9.1 & 7.5 & 2.7 \\
\hline Região do Médio Paraíba & 6.8 & 11.1 & 12.0 & 5.1 \\
\hline Região Centro-Sul Fluminense & 1.2 & 6.6 & 0.8 & 1.3 \\
\hline Região da Costa Verde & 1.1 & 2.7 & 1.4 & 1.0 \\
\hline \multicolumn{5}{|l|}{2010} \\
\hline Estado do Rio de Janeiro & 100.0 & 100.0 & 100.0 & 100.0 \\
\hline Região Metropolitana & 64.8 & 15.0 & 40.8 & 74.5 \\
\hline Região Noroeste Fluminense & 1.0 & 10.7 & 0.5 & 1.2 \\
\hline Região Norte Fluminense & 12.5 & 20.2 & 28.7 & 6.1 \\
\hline Região Serrana & 4.1 & 25.1 & 4.1 & 4.0 \\
\hline Região das Baixadas Litorâneas & 5.9 & 8.5 & 10.7 & 4.0 \\
\hline Região do Médio Paraíba & 7.4 & 9.7 & 12.1 & 5.5 \\
\hline Região Centro-Sul Fluminense & 1.1 & 7.3 & 0.8 & 1.2 \\
\hline Região da Costa Verde & 3.0 & 3.4 & 2.2 & 3.4 \\
\hline
\end{tabular}

Fonte: IBGE, Contas regionais 2012, Produto Interno Bruto dos Municípios 2012; Fundação CEPERJ.

Já a distribuição do VAB pelas atividades econômicas nas regiões no ano de 2010 (Tabela 2) permite observar como se dá a divisão territorial ou inter-regional do trabalho no 
território fluminense segundo a especialização setorial, quando se compara a participação dos setores econômicos de cada região à média do ERJ.

Em que pese a reduzida participação da agropecuária no total da atividade econômica fluminense (0,4\% em 2010), há regiões que ainda apresentam participação do setor primário relevante na distribuição interna dos setores econômicos, tais como a Noroeste Fluminense $(4,3 \%)$, a Serrana $(2,6 \%)$ e a Centro-Sul Fluminense $(2,7 \%)$, sendo estas as que se destacam nesta atividade. No que diz respeito à atividade industrial, as regiões que superam o ERJ $(28,1 \%)$ e se caracterizam como mais industrializadas são a Norte Fluminense $(64,4 \%)$, a das Baixadas Litorâneas $(50,7 \%)$ e a do Médio Paraíba $(45,9 \%)$, e as que apresentam participações em serviços superiores à média estadual (71,5\%) são a Metropolitana (82,2\%), a Noroeste Fluminense $(81,1 \%)$, a Centro-Sul Fluminense $(77,0 \%)$ e a da Costa Verde $(79,0 \%)$.

Tabela 2: Participação do valor adicionado bruto dos setores econômicos das Regiões de Governo no valor adicionado bruto total das Regiões de Governo do Estado do Rio de Janeiro - 2000-2010

\begin{tabular}{|c|c|c|c|c|}
\hline Estado e Regiões de Governo & Total & Agropecuária & Indústria & Serviços \\
\hline \multicolumn{5}{|l|}{2000} \\
\hline Estado do Rio de Janeiro & 100.0 & 0.7 & 24.0 & 75.3 \\
\hline Região Metropolitana & 100.0 & 0.1 & 17.9 & 82.0 \\
\hline Região Noroeste Fluminense & 100.0 & 6.0 & 14.9 & 79.1 \\
\hline Região Norte Fluminense & 100.0 & 2.2 & 63.1 & 34.7 \\
\hline Região Serrana & 100.0 & 3.6 & 17.8 & 78.6 \\
\hline Região das Baixadas Litorâneas & 100.0 & 1.5 & 46.5 & 51.9 \\
\hline Região do Médio Paraíba & 100.0 & 1.1 & 42.6 & 56.3 \\
\hline Região Centro-Sul Fluminense & 100.0 & 3.6 & 16.0 & 80.4 \\
\hline Região da Costa Verde & 100.0 & 1.6 & 29.6 & 68.7 \\
\hline \multicolumn{5}{|l|}{2010} \\
\hline Estado do Rio de Janeiro & 100.0 & 0.4 & 28.1 & 71.5 \\
\hline Região Metropolitana & 100.0 & 0.1 & 17.7 & 82.2 \\
\hline Região Noroeste Fluminense & 100.0 & 4.3 & 14.6 & 81.1 \\
\hline Região Norte Fluminense & 100.0 & 0.7 & 64.4 & 35.0 \\
\hline Região Serrana & 100.0 & 2.6 & 27.8 & 69.6 \\
\hline Região das Baixadas Litorâneas & 100.0 & 0.6 & 50.7 & 48.7 \\
\hline Região do Médio Paraíba & 100.0 & 0.6 & 45.9 & 53.5 \\
\hline Região Centro-Sul Fluminense & 100.0 & 2.7 & 20.2 & 77.0 \\
\hline Região da Costa Verde & 100.0 & 0.5 & 20.5 & 79.0 \\
\hline
\end{tabular}

Fonte: IBGE, Contas regionais 2012, Produto Interno Bruto dos Municípios 2012; Fundação CEPERJ. 
Portanto, tendo em vista a participação dominante no VAB de cada setor econômico, poder-se-ia dizer que a Serrana é a região que tem na atividade primária relevante contribuição para sua estrutura econômica, enquanto as regiões Noroeste Fluminense e Centro-Sul Fluminense, que também se destacam na atividade, têm relevante participação do setor serviços; as regiões industriais seriam a Norte Fluminense, a das Baixadas Litorâneas e a do Médio Paraíba, e a região com maior característica em serviços seria a Metropolitana.

\section{2 Índices de localização e especialização}

O uso de indicadores de análise regional neste momento se propõe comparar, por um lado, como se expressam setores econômicos em regiões distintas (abordagem setorial) e, por outro, o grau de diversificação/especialização de cada região (abordagem regional). Para o primeiro propósito, optou-se por utilizar o Quociente de Localização (QL) e, para o segundo, o Coeficiente de Especialização (CE), na medida em que atendem aos requisitos desejados e são complementares, permitindo leituras alternativas à da participação setorial da sessão anterior.

O Quociente de Localização (QL) é determinado pela razão entre a participação do $\mathrm{VAB}$ do setor $i$ na região $j$ em relação ao $\mathrm{VAB}$ total na região $j$ e a participação do $\mathrm{VAB}$ do setor $i$ em relação ao $\mathrm{VAB}$ total, na forma como segue:

$$
Q L_{i j}=\frac{\left[\frac{V A B_{i j}}{\sum_{j} V A B_{i j}}\right]}{\left[\frac{\sum_{i} V A B_{i j}}{\sum_{i} \sum_{j} V A B_{i j}}\right]} \quad 0 \leq Q L \leq \infty
$$

e indica o nível de especialização da atividade produtiva regional em relação à sua região de abrangência. Seu valor varia de 0 a infinito, e sua interpretação pode revelar três situações: a) se $\mathrm{QL}=1$, a especialização da região $i$ no setor $j$ é idêntica à espacialização do conjunto das regiões analisadas neste setor; b) se $\mathrm{QL}<1$, a especialização da região $i$ no setor $j$ é inferior à especialização do conjunto das regiões analisadas neste setor, e c) se QL > 1, a especialização da região $i$ no setor $j$ é superior à especialização do conjunto das regiões analisadas neste setor. 
Já o Coeficiente de Especialização (CE) tem como premissa avaliar o grau de concentração que uma região possui em relação aos setores de atividade econômica nela existentes, sendo, pois, uma medida relativa com elevada capacidade de síntese e, quanto mais próximo de um, mais especializada é a região em estudo. Sua formulação consiste no somatório do módulo dos desvios da importância que o setor $j$ assume na região $i$ e a importância que esse mesmo setor assume no total das regiões, na forma que segue:

$$
C E=\frac{1}{2} \sum_{i}\left[\left(\frac{V A B_{i j}}{\sum_{i} V A B_{i j}}-\frac{\sum_{j} V A B_{i j}}{\sum_{i} \sum_{j} V A B_{i j}}\right)\right] \quad 0 \leq C E \leq 1
$$

Uma particularidade específica do CE é a de que seus resultados são altamente subjetivos e dependeriam da comparação com uma "região de referência" (Boisier, 1980:48), para que se torne útil, mas a definição desta também é subjetiva, e sua busca exigiria exaustiva exploração em recortes diversos dos que estão em estudo aqui. Os resultados de ambos os indicadores encontram-se na Tabela 3. 
Tabela 3: Quociente de localização e coeficiente de especialização nas Regiões de Governo do Estado do Rio de Janeiro - 2000/2010

\begin{tabular}{|c|c|c|c|c|}
\hline \multirow[t]{2}{*}{ Regiões de Governo } & \multicolumn{3}{|c|}{ Quociente de localização } & \multirow{2}{*}{$\begin{array}{l}\text { Coeficiente } \\
\text { de } \\
\text { especializa- } \\
\text { ção }\end{array}$} \\
\hline & Agropecuária & Indústria & Serviços & \\
\hline \multicolumn{5}{|l|}{2000} \\
\hline Região Metropolitana & 0.19 & 0.85 & 1.25 & 0.07 \\
\hline Região Noroeste Fluminense & 10.62 & 0.73 & 1.23 & 0.09 \\
\hline Região Norte Fluminense & 1.97 & 1.55 & 0.27 & 0.41 \\
\hline Região Serrana & 5.37 & 0.73 & 1.03 & 0.06 \\
\hline Região das Baixadas Litorâneas & 1.54 & 1.27 & 0.45 & 0.23 \\
\hline Região do Médio Paraíba & 1.49 & 1.62 & 0.68 & 0.19 \\
\hline Região Centro-Sul Fluminense & 5.80 & 0.71 & 1.14 & 0.08 \\
\hline Região da Costa Verde & 0.89 & 0.44 & 0.33 & 0.07 \\
\hline \multicolumn{5}{|l|}{2010} \\
\hline Região Metropolitana & 0.23 & 0.63 & 1.15 & 0.11 \\
\hline Região Noroeste Fluminense & 10.19 & 0.52 & 1.13 & 0.13 \\
\hline Região Norte Fluminense & 1.61 & 2.29 & 0.49 & 0.37 \\
\hline Região Serrana & 6.09 & 0.99 & 0.97 & 0.02 \\
\hline Região das Baixadas Litorâneas & 1.45 & 1.81 & 0.68 & 0.23 \\
\hline Região do Médio Paraíba & 1.32 & 1.64 & 0.75 & 0.18 \\
\hline Região Centro-Sul Fluminense & 6.48 & 0.72 & 1.08 & 0.08 \\
\hline Região da Costa Verde & 1.11 & 0.73 & 1.10 & 0.08 \\
\hline
\end{tabular}

Fonte: IBGE, Produto interno bruto dos municípios. Elaboração própria.

Tem-se por premissa que o QL, medida cujo uso largamente difundido sugere superioridade ante o $\mathrm{CE}$, pouco utilizado, terá suas indicações tratadas em caráter menos rigoroso que seu complemento. Dessa forma, o que se observa na distribuição locacional dos setores econômicos nas regiões fluminenses é que: 1) valores mais expressivos de QL foram encontrados na agropecuária nos dois períodos de tempo, mas com maior expressividade conjunta em 2010 nas regiões Noroeste Fluminense (10,62), Serrana $(6,09)$ e Centro-Sul Fluminense (6,48); além destas, valores maiores que a unidade sugerem que na Norte Fluminense, na das Baixadas Litorâneas, na do Médio Paraíba e na da Costa Verde também haveria participação razoável da atividade; 2) a indústria, por outro lado, apresenta QL significativos em 2010 apenas nas regiões Norte Fluminense (2,29), das Baixadas Litorâneas $(1,81)$ e do Médio Paraíba $(1,64)$, as mesmas que no ano de 2000 e, quanto aos serviços em 2010, despontam as regiões Metropolitana $(1,15)$, Noroeste Fluminense $(1,13)$, Centro-Sul Fluminense $(1,08)$ e da Costa Verde $(1,10)$. 
Já quanto aos resultados obtidos a partir do CE, as regiões mais especializadas seriam a Norte Fluminense $(0,37)$, a das Baixadas Litorâneas $(0,23)$ e a do Médio Paraíba $(0,18)$, mas com valores relativamente baixos, sendo que, no caso da primeira, que, segundo a participação por setor econômico, demonstrou maior dominância do secundário na passagem de 2000 para 2010, teve seu valor reduzido. A seu favor, indicou as regiões industriais, nas quais há elevada dominância de indústria e serviços, mas não captou a importância do setor primário existente na Noroeste Fluminense, na Serrana e na Centro-Sul Fluminense, que também apresentam participação relevante em serviços.

Comparando os critérios utilizados, da participação por setor econômico e do QL como indicador de especialização setorial, observa-se que: a) no que diz respeito ao setor primário, além da região Serrana sugerida pela primeira alternativa, cabe incluir as regiões Noroeste Fluminense e do Centro-Sul Fluminense como relevantes localizações da agropecuária, mas as demais, que também apresentaram QLs maiores que a unidade, não têm nessa atividade participação relevante; b) no que diz respeito ao setor secundário, houve convergência em ambos os critérios, destacando como especializadas as regiões Norte Fluminense, das Baixadas Litorâneas e a do Médio Paraíba, e c) quanto ao setor terciário, além da região Metropolitana sugerida pelo primeiro critério e confirmada no segundo, as regiões Noroeste Fluminense, Centro-Sul Fluminense e da Costa Verde foram inseridas por apresentarem QLs elevados.

Dessa forma, a divisão territorial do trabalho fluminense demonstra que há regiões que possuem mais de uma função, tais como a Noroeste Fluminense (agropecuária e serviços) e a Centro-Sul Fluminense (idem), enquanto as demais contribuem com apenas uma atividade dominante: Serrana (agropecuária); Norte Fluminense, das Baixadas Litorâneas e a do Médio Paraíba (indústria), e da Costa Verde e Metropolitana (serviços). Particular situação é devida à última, a maior região do estado, e que contém elevada densidade de estabelecimentos industriais e acumula investimentos nesta atividade, inclusive de natureza mais recente, relacionados à petroquímica em seu lado leste. $\mathrm{O}$ indicador utilizado para a discriminação (VAB), per se, poderia sugerir tendenciosidade para a discriminação, mas há outras particularidades relacionadas à atual configuração das atividades industriais que apontam em outra direção, como se verá a seguir. 


\section{Produtividade regional e participação industrial}

A relação entre a expansão econômica no território e as mudanças na divisão do trabalho entre regiões já foi objeto de reflexão em Oliveira e Reichstul (1973), que consideraram como condição primordial a mobilidade dos capitais, e dos setores econômicos em particular. A este respeito, deixaram claro que o setor serviços não tem capacidade de influenciar as alterações da divisão territorial do trabalho, dado que não possui mobilidade como as atividades primárias e secundárias:

Quando se pensa em divisão inter-regional do trabalho, a mobilidade é uma condição sine qua non para sua concretização. O setor serviços, devido a sua pouca mobilidade, escapa a uma redefinição da divisão do trabalho e mantém a mesma posição para cada região, apesar das alterações dos outros setores. Será o comportamento dos setores agrícola e industrial que irá determinar a importância dos serviços para cada região, e não o comportamento do setor serviços de uma para outra região. (Oliveira e Reichstul, 1973:143)

Tendo em vista a subordinação do terciário aos movimentos dos demais setores econômicos, e que no Estado do Rio de Janeiro os investimentos industriais têm demonstrado capacidade para promover migrações inter-regionais, ganhos de participação da indústria na distribuição do VAB e alterações na divisão territorial do trabalho, devem-se em grande medida ao secundário as mudanças, haja vista que o setor primário tem baixa participação.

De outra forma, nas regiões alcançadas pelos investimentos, que registraram aumento na participação do $\mathrm{VAB}$ total e industrial, a produtividade regional pode ter-se elevado consideravelmente, uma vez que maior participação do setor secundário está diretamente associada à sua elevação. A esse respeito, Trotsky (1977) já afirmava que "o nível econômico de uma nação é medido, essencialmente, pela produtividade do trabalho, a qual, pelo seu lado, depende da densidade da indústria na economia geral do país".

Para os fins deste trabalho, o indicador de produtividade do trabalho para cada uma das regiões consideradas será calculado a partir da razão entre o VAB dos anos censitários (2000 e 2010) ${ }^{2}$ e o número de ocupados para cada um dos anos do Censo Demográfico, que abrange todas as categorias de inserção na ocupação (empregados com e sem carteira, conta

\footnotetext{
${ }^{2}$ A série de dados do Produto Interno Bruto dos municípios do IBGE se inicia em 1999 e alcança, até o presente momento, o ano de 2010. Portanto, apenas nos anos de 2000 e 2010 é possível calcular o produto por trabalhador.
} 
própria e empregadores). Já a densidade regional da indústria será obtida a partir da participação do VAB industrial no VAB total de cada região, expressando o peso do setor secundário na estrutura econômica interna das regiões. Mediante os resultados em cada indicador, avaliaremos se as regiões que receberam investimentos e aumentaram suas participações industriais são as que detêm maior produto por trabalhador, conforme sugerido por Trotsky.

Tabela 4: Produto por trabalhador e razão entre o produto por trabalhador regional e o do total do Estado do Rio de Janeiro, segundo as Regiões de Governo do Estado do Rio de Janeiro - 2000/2010

\begin{tabular}{|c|c|c|c|c|}
\hline Estado e Regiões de Governo & $\begin{array}{c}\text { Produto por } \\
\text { trabalhador }(\mathrm{R} \$) \\
(2000)\end{array}$ & $\begin{array}{c}\text { Razão entre a } \\
\text { região e o estado } \\
(2000)(\%)\end{array}$ & $\begin{array}{c}\text { Produto por } \\
\text { trabalhador }(\mathrm{R} \$) \\
(2010)\end{array}$ & $\begin{array}{c}\text { Razão entre a } \\
\text { região e o estado } \\
(2010)(\%)\end{array}$ \\
\hline Estado do Rio de Janeiro & 21367 & - & 48158 & \\
\hline Região Metropolitana & 21199 & 99.2 & 42279 & 87.8 \\
\hline Região Noroeste Fluminense & 11751 & 55.0 & 25346 & 52.6 \\
\hline Região Norte Fluminense & 32801 & 153.5 & 115374 & 239.6 \\
\hline Região Serrana & 14826 & 69.4 & 36201 & 75.2 \\
\hline Região das Baixadas Litorâneas & 21162 & 99.0 & 56593 & 117.5 \\
\hline Região do Médio Paraíba & 26951 & 126.1 & 66628 & 138.4 \\
\hline Região Centro-Sul Fluminense & 14863 & 69.6 & 40812 & 84.7 \\
\hline Região da Costa Verde & 20128 & 94.2 & 94529 & 196.3 \\
\hline
\end{tabular}

Fonte: IBGE, Censos Demográficos; Contas regionais 2012, Produto Interno Bruto dos Municípios 2012;

Fundação CEPERJ.

Como se pode observar na Tabela 4, no ano de 2000 as únicas regiões que possuíam produtividade superior à do ERJ eram a Norte Fluminense (53,5\% superior) e a do Médio Paraíba $(26,1 \%)$, o que sugere que os investimentos na extração mineral e nos setores siderúrgido, metal-mecânico e automobilístico no século passado já faziam efeito na produtividade da mão de obra. Desta forma, e na medida em que se manteve a orientação regional do fluxo de recursos para investimentos, se esperaria que os níveis de produtividade das regiões receptoras se mantivessem superiores aos das demais.

De acordo com as informações de 2010 há melhorias na produtividade relativa da maioria das regiões, exceto na Noroeste Fluminense, a pior situação no ERJ, com redução para próximo à metade da média $(52,6 \%)$ estadual. Recorde-se que, na divisão territorial do 
trabalho, esta região apresenta elevada participação no VAB agropecuário, e tem, em sua estrutura interna, participação do terciário superior à média.

Nas demais regiões, entre aquelas em que o produto por trabalhador já era superior à média em 2000 e que se caracterizam como industriais, a região do Médio Paraíba aumentou a distância (38,4\% acima), e o crescimento mais significativo se observou na Norte Fluminense, cuja produtividade do trabalho se elevou a mais que o dobro da média em 2010 (139,6\% maior do que a do Estado). Além destas, outras regiões passaram a apresentar produtividade superior à do ERJ, sendo elas: a das Baixadas Litorâneas (17,5\%), também caracterizada como industrial, e a da Costa Verde (96,3\%). Esta última, sem setor primário e com um quinto da renda gerada pelo secundário (oriunda dos setores de energia e metalúrgico), foge à regra sugerida por Trotsky, já que possui baixa densidade industrial relativa.

Apesar da situação atípica relacionada à região da Costa Verde, a partir das informações levantadas e dos indicadores analisados, confirmaram-se as ponderações de Trotsky de que o produto por trabalhador é maior nas regiões que apresentam maior densidade industrial, tomando-se o valor adicionado bruto como referência. Uma alternativa a este exercício seria trabalhar com informações específicas do setor industrial, tais como o valor de transformação industrial (VTI) para o cálculo da densidade industrial regional, mas, apesar da Pesquisa Industrial Anual (PIA) do IBGE levantar informações com este objetivo, não gera dados para o nível municipal e/ou regional.

No entanto, a partir do uso do VTI para as PIAs de 1996, 2000 e 2005, Rosendo e Britto (2011) observaram aspectos que auxiliam o entendimento dos resultados alcançados regionalmente até aqui, tais como: 1) no que se refere à participação das atividades ligadas à atividade petrolífera, somadas as contribuições de refino de petróleo $(20,1 \%)$ e de extração de petróleo e gás (31,6\%), em 2005 já ultrapassavam mais da metade de todo o valor adicionado pela indústria geral, sinal de elevada dependência, e que pode ter-se acentuado recentemente; 2) com relação à produtividade por trabalhador: i) comparativamente à indústria nacional, seja para o total da indústria de transformação ou para a extrativa mineral, o trabalhador fluminense era mais produtivo, com destaque para a extração de petróleo e gás, fabricação e montagem de veículos automotores e metalurgia básica, setores que vêm participando da retomada da atividade industrial no Estado; ii) comparativamente aos estados do Sudeste no 
ano 2000, o trabalhador fluminense era mais produtivo que os das demais unidades da Federação.

Os autores atribuem a superioridade obtida ao crescimento puxado por setores "densos em capital, que apresentam elevada concentração e importantes economias de escala, como ocorre com os setores ligados a E\&P [extração de petróleo e gás] e refino de petróleo e gás" (Rosendo e Britto, 2011:13). Neste ponto, identificamos elementos que expliquem o elevado resultado alcançado pela região Norte Fluminense comparativamente às demais, no que tange ao produto por trabalhador (Tabela 4), haja vista que a atividade de extração de petróleo e gás nela se concentra. Já a atividade de refino de petróleo e gás, concentrada basicamente na região Metropolitana, não contribuiu ainda para elevar a produtividade, que se reduziu entre 2000 e 2010 comparativamente à média do Estado.

Num outro ponto levantado pelos autores, há favorecimento à condição da região Norte Fluminense, que em decorrência a diferencia das demais. Como mencionado anteriormente, nos territórios "adiantados" há concentração de capital e convergência de processos, o que se obtém a partir da igualização com outros espaços absolutos que, a exemplo do existente naquela região, também desenvolvem a mesma atividade. E como já se avizinha a dois terços da renda gerada a predominância da atividade industrial, esta elevada densidade aumenta a capacidade de inovação, de disseminação tecnológica e produção, segundo Rosendo e Britto (2011), que por fim eleva os níveis de produtividade regional, como mencionado por Trotsky (1977).

\section{Conclusões}

A divisão territorial do trabalho fluminense, tomando por base a proposição de Oliveira e Reichstul (1973) e o produto por trabalhador como indicador de produtividade, como sugerido por Faria (1976), se apresentou relativamente bem definida a partir dos critérios utilizados de participação na distribuição da riqueza regional e por setor econômico, e da especialização medida pelo QL. Segundo a geração de riqueza por setor econômico e o QL das regiões no Estado do Rio de Janeiro, aquelas mais a norte, com maior participação do setor primário, relativamente baixa densidade industrial e com setor serviços próximo e acima de $70 \%$ do valor adicionado bruto, seriam mais agrícolas. Estas mesmas regiões, que não contam com participação industrial relevante, apresentam níveis de produtividade inferiores 
às das demais, em situação oposta à mencionada por Trotsky (1977). De acordo com as informações analisadas neste trabalho, seriam elas as regiões Serrana, Noroeste Fluminense e Centro-Sul Fluminense, sendo que a segunda, que já apresentava em 2000 o pior resultado, apresentou declínio em relação à média e na produtividade relativa ante as demais, no ano de 2010.

Já a região que tem características tipicamente terciárias, a Metropolitana, mas também possui maior volume de estabelecimentos industriais, conta com importantes investimentos feitos e em curso, ligados à cadeia petrolífera e logística (Riopol e COMPERJ, e Arco Metropolitano, respectivamente), mas possui produtividade inferior à média do Estado. Somam-se a ela as regiões Noroeste Fluminense e Centro-Sul Fluminense fortemente agropecuárias, e a região da Costa Verde, que, apesar de possuir relativamente baixa densidade industrial e ter elevada participação do terciário, é a segunda mais produtiva e apresentou migração mais recente de acordo com estudos anteriores.

Por último, as regiões com o maior nível de produtividade do estado são aquelas que possuem elevada participação industrial, como defendido por Trotsky. São elas a do Norte Fluminense, a do Médio Paraíba e a das Baixadas Litorâneas, sendo que a última se beneficia da vizinhança com a primeira e do fluxo migratório recente, diferentemente da segunda, cuja migração tem como características motivações antigas. As três apresentaram evidências de dinamismo econômico, sendo que as duas primeiras alcançaram resultados significativos nos principais indicadores relacionados à geração de riquezas e volume de negócios (Medeiros Junior, 2012b, 2013b), mas, por outro lado, passaram a ter seus mercados de trabalho pressionados, passando a uma situação desconfortável (Medeiros Junior, 2012a, 2013b) e que carece de maior observação por parte dos planejadores regionais.

A região de destaque segundo os indicadores analisados, no entanto, é a Norte Fluminense, que, além de ter consolidado a condição de segunda maior do ERJ em 2010 com base no total do $\mathrm{VAB}$, é a maior de todas em termos industriais para o mesmo indicador e a que possui o maior produto por trabalhador empregado. A julgar pela produtividade consideravelmente superior à da região Metropolitana (RMRJ), no próximo Censo Demográfico, quando será possível atualizar as informações utilizadas neste trabalho, a distância entre as duas regiões será menor, considerando-se que o Norte Fluminense apresenta taxa de crescimento populacional superior à da RMRJ, migração elevada, e há indicações de aumento do nível de atividade econômica, decorrente, entre outros fatores, da presença da 
atividade de extração de petróleo e gás, a que possui a maior produtividade por trabalhador segundo a PIA/IBGE.

Por fim, tendo em vista que a literatura sugere outros indicadores para melhor apreensão da divisão territorial do trabalho, dentre os quais maior aprofundamento na estrutura produtiva, condições socioeconômicas e hierarquia funcional, por exemplo, os próximos passos deverão ser dados neste sentido, para maior detalhamento e conhecimento da realidade aqui exposta, em benefício de melhor planejamento regional. A dinâmica decorrente da expansão capitalista no interior indica que se acentuará a diferenciação espacial e a divisão territorial do trabalho, com maior proeminência das regiões industriais em detrimento das demais, menos produtivas, e que merecem atenção quanto ao "atraso" que se aprofundará devido ao desenvolvimento desigual no território fluminense.

\section{Referências Bibliográficas}

BOISIER, Sergio. Técnicas de análisis regional con información limitada. Santiago de Chile: CEPAL, 1980. 170 p. (Cuadernos del ILPES, n. 27)

BORCHARDT, Julian. O capital: edição resumida. 7. ed. Rio de Janeiro: Ed. LTC, 1982.

CORRÊA, Roberto Lobato. Estudos sobre a rede urbana. Rio de Janeiro: Bertrand Brasil, 2006.

FARIA, V. O sistema urbano brasileiro. Um resumo das características e tendências recentes. Estudos CEBRAP, 18, pp. 93-115, 1976.

Divisão social do trabalho, especialização funcional e crescimento urbano: o caso da macrometrópole paulista. In: II ENCONTRO NACIONAL DE ESTUDOS POPULACIONAIS, Anais..., Águas de São Pedro (SP), vol. 2, pp. 745-775, 1980.

FREDRICH, O. M. B. L.; DAVIDOVICH, F. A configuração espacial do sistema urbano brasileiro como expressão no território da divisão social do trabalho. Revista Brasileira de Geografia, Rio de Janeiro, vol. 44, n. 4, pp. 541-590, out./dez. 1982.

FUNDAÇÃO CEPERJ. Anuário estatístico do Rio de Janeiro 2010. Rio de Janeiro, 2011. 1 CD-ROM. 
. Estado do Rio de Janeiro: um breve balanço da década. Rio de Janeiro, [2012]. 26 p. Disponível em: <http://www.ceperj.rj.gov.br/>. Acesso em: 10 jul. 2012.

Produto interno bruto dos municípios - 2010: Estado do Rio de Janeiro, 2012. Disponível em: <http://www.ceperj.rj.gov.br/ceep/pib/PIB_municipios_RJ_2010.pdf>. Acesso em: 3 jan. 2012.

INSTITUTO NACIONAL DE ESTATÍSTICA. Medidas de especialização regional. Revista de Estudos Regionais, Lisboa, Direcção Regional de Lisboa e Vale do Tejo, n. 5, pp. 65$72,2003$.

KALECKI, M. Teoria da dinâmica econômica: ensaio sobre as mudanças cíclicas e a longo prazo da economia capitalista. São Paulo: Nova Cultural, 1985.

KEYNES, J.M. A teoria geral do emprego, do juro e da moeda. São Paulo: Nova Cultural, 1988.

MARX, Karl. O capital: crítica da economia política. vol. 1, L. 1, Rio de Janeiro: Nova Cultural, 1996. (Os Economistas).

MASSEY, D. Spatial divisions of labor: social structures and the geography of production. New York: Routledge, 1995.

MEDEIROS JUNIOR, H. O papel das cidades e a realidade municipal fluminense: métricas e indicadores para planejamento. In: XV SEMANA IPPUR: Espaço e vida pública, território, imaginário, poder, 2009. Rio de Janeiro. SEMANA IPPUR, 15, 2009, Rio de Janeiro, Anais... UFRJ/IPPUR, 2009. 1 CD-ROM.

. Mudanças de estado do mercado de trabalho fluminense: diferenças regionais entre 2000 e 2010. In: ENCONTRO NACIONAL DE ESTUDOS POPULACIONAIS: transformações na população brasileira: complexidades, incertezas e perspectivas (18, 2012a: Águas de Lindóia, SP). Anais eletrônicos... Disponível em: <http://www.abep.nepo.unicamp.br/xviii/anais/site/index.php>.

Dinâmica econômica e o mercado de trabalho fluminense entre 2000 e 2010. In: SEMINÁRIO DINÂMICA ECONÔMICA E DESENVOLVIMENTO REGIONAL, 1, 2012b, Uberaba. Anais... Uberaba, Universidade Federal do Triângulo Mineiro, 2012b. 1 CD-ROM.

. Desconcentração econômica e atratividade regional no Estado do Rio de Janeiro entre 2000 e 2010. Revista Cadernos do Desenvolvimento Fluminense, Rio de Janeiro, n. 1, 
fev.

$2013 \mathrm{a}$.

Disponível

em:

<http://www.cadernosdodesenvolvimento.ceperj.rj.gov.br/index.php/cdf>.

. Dinâmica populacional e econômica regional, e o mercado de trabalho fluminense entre 2000 e 2010. In: ENCONTRO DA ANPUR: desenvolvimento, planejamento e governança, 15, 2013b, Recife. Anais... Recife, ANPUR, 2013b. 1 CD-ROM

. Mudanças na divisão inter-regional do trabalho fluminense: desenvolvimento desigual da renda interna entre 2000 e 2010. In: SEMANA IPPUR: planejamento, desigualdade e justiça social: desafios para as cidades e regiões, 19, 2013c, Rio de Janeiro, Anais... Rio de Janeiro, UFRJ/IPPUR, 2013c.

MEDEIROS JUNIOR, H.; GRAND JUNIOR, J. Distribuição dos empregos formais na cidade do Rio de Janeiro: uma análise exploratória. In: SEMANA IPPUR: um território em disputa, 16, 2010, Rio de Janeiro, Anais... Rio de Janeiro, UFRJ/IPPUR, 2010. Disponível em: <http://www.ippur.ufrj.br/download/semana_pur_2010/completos/helcio_joao.pdf>.

. Geografia econômica regional fluminense nos anos 00: aumento de riqueza, expectativa de pobreza. In: ENCONTRO DA ANPUR: quem planeja o território? Atores, arenas e estratégias, 14, 2011, Rio de Janeiro. Anais... Rio de Janeiro, ANPUR, 2011. 1 CD-ROM

Distribuição dos empregos formais na cidade do Rio de Janeiro: uma análise espacial. In: ENCONTRO DA ANPUR: quem planeja o território? Atores, arenas e estratégias, 14, 2011, Rio de Janeiro. Anais... Rio de Janeiro, ANPUR, 2011. 1 CD-ROM

MELO, H. P.; CONSIDERA, C. M. Industrialização fluminense - 1930-1980. Revista do Rio de Janeiro, vol. 1, n. 3, UFF, Niterói, 1986.

MOHUN, S. Divisão do trabalho. In: BOTTOMORE, T. Dicionário do pensamento marxista. Rio de Janeiro: Jorge Zahar, 1988.

MYRDAL, Gunnar. Teoria econômica e regiões subdesenvolvidas. 3. ed. Rio de Janeiro: Saga, 1972.

NATAL, Jorge L.A. O Estado do Rio de Janeiro pós-1995: dinâmica econômica, rede urbana e questão social. Rio de Janeiro: Pubblicati, 2005.

OLIVEIRA, A. Território e mercado de trabalho: discursos \& teorias. São Paulo: Editora UNESP, 2006. 
OLIVEIRA, F. J. G. Reestruturação produtiva: território e poder no Estado do Rio de Janeiro. Rio de Janeiro: Garamond, 2008.

OLIVEIRA, Francisco; REICHSTUL, Henri-Philippe. As mudanças na divisão inter-regional do trabalho no Brasil. Estudos CEBRAP, 4, pp. 131-168, 1973.

PIQUET, R.P.S. Reestruturação do espaço regional e urbano no Brasil: o poder do Estado e dos grandes investimentos. Rio de Janeiro: UFRJ/IPPUR, 1993.

RODRIGUES, Daniel. Marx e a divisão social do trabalho, uma resposta atual. In: IV CONFERENCIA INTERNACIONAL "LA OBRA DE CARLOS MARX Y LOS DESAFIOS DEL SIGLO XXI", Cuba, 5 a 8 de mayo, 2008.

ROSENDO, R. C.; BRITTO, J. Evolução da densidade industrial do Estado do Rio de Janeiro: análise comparativa com os estados do sudeste brasileiro-2000/2005. In: ENCONTRO NACIONAL DE ECONOMIA, 39, 2011, Foz do Iguaçu. Anais... Foz do Iguaçu, ANPEC, 2011. Disponível em: <www.anpec.org.br>.

SILVA, R. D. Rio de Janeiro, crescimento, transformações e sua importância para a economia nacional (1930-2000). Dissertação de Mestrado. Campinas: UNICAMP, 2004.

. Indústria e desenvolvimento regional no Rio de Janeiro (1990-2008). Rio de Janeiro: Editora FGV, 2012.

SIMÕES, R. F. Métodos de análise regional e urbana: diagnóstico aplicado ao planejamento. Belo Horizonte: UFMG/Cedeplar, 2005. 31 p. (Texto para discussão, n. 259).

SMITH, Adam. A riqueza das nações: investigação sobre sua natureza e suas causas. São Paulo: Nova Cultural Ltda, 1996. (Coleção Os economistas).

SMITH, Neil. Desenvolvimento desigual: natureza, capital e a produção do espaço. Rio de Janeiro: Bertrand Brasil, 1988. 250p.

TROTSKY, L. A história da revolução russa. 2. ed. Rio de Janeiro: Paz e Terra, 1977. Disponível em: <http://www.marxists.org/portugues/trotsky/1930/historia/cap01.htm>. Acesso em 17 de fevereiro de 2012. 